Disponível em

http://www.anpad.org.br/rac

RAC, Rio de Janeiro, v. 17, n. 6, art. 2, pp. 661-678, Nov./Dez. 2013

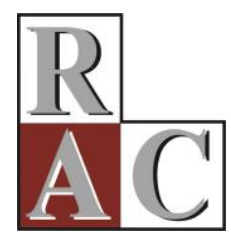

\title{
A Pluralidade nas Transações de Cana-de-açúcar no Oeste Paulista
}

The Plurality of Sugar Cane Transactions in Western São Paulo

Cristiane Feltre

E-mail: crisfeltre@yahoo.com

Pontifícia Universidade Católica de Campinas - CEA/PUC-Campinas

Rodovia D. Pedro I, km 136, Parque das Universidades, 13086-900, Campinas, SP, Brasil.

Luiz Fernando de Oriani e Paulillo

E-mail: dlfp@power.ufscar.br

Universidade Federal de São Carlos - DEP/UFSCAR DEP/UFSCar, Rodovia Washington Luis, SP 310; km 235, 13565-905, São Carlos, SP, Brasil. 


\title{
Resumo
}

A pluralidade nas transações é estudada em várias atividades econômicas, em especial as franquias. Há estudos desenvolvidos sobre a análise da transação, porém esses estudos não alcançam o conjunto das transações que as empresas adotam para um mesmo resultado. No abastecimento de cana-de-açúcar para as usinas, a organização das transações em mais de uma estrutura de coordenação foi observada na região oeste do Estado de São Paulo. Este artigo tem como objetivo principal analisar quais as razões para a adoção de formas singulares ou plurais de coordenação dos negócios de fornecimento de cana nas usinas da referida região. Para tanto, foi realizada uma pesquisa de campo com aplicação de entrevistas com os responsáveis pelas decisões de abastecimento de cana nas usinas de açúcar e/ou álcool. Os resultados indicam que há elementos da abordagem de economia dos custos de transação que explicam a adoção de formas plurais de coordenação dos negócios e que contribuem para o entendimento do processo de adaptação das empresas nos mercados, principalmente quando se compreende que a empresa é um nexo de negociações e não apenas uma função da produção. Assim, as ações que explicam a estratégia empresarial ganham maior complexidade e trazem a novidade de outros ganhos com a adoção da pluralidade de gestão na negociação pela firma.

Palavras-chave: formas plurais de governança; usinas de açúcar e/ou álcool; oeste do Estado de São Paulo.

\begin{abstract}
Plural forms in transactions are a phenomenon that has been studied in various economic activities, especially in franchises. There exist studies that have analyzed such transactions, but these studies do not cover the set of transactions that companies adopt seeking the same result. More than one governance structure was observed in terms of organizing transactions to supply sugarcane to plants in the western region of São Paulo state. This article aims to analyze the main factors which justify the choice of singular or plural governance forms in plants of this region. We conducted a field research by interviewing decision makers in the supply chain of sugarcane to sugar and/or ethanol mills. The results indicate elements from transaction cost economics can be used to explain the adoption of plural forms of business coordination and contribute to understanding companies' market adaptation processes, especially when a company is viewed as a nexus of negotiations and not merely a production function. Thus, actions that explain business strategy gain greater complexity and bring the novelty of other gains through the adoption of plural management firm transactions.
\end{abstract}

Key words: plural forms of governance; sugar/ethanol plants; West of São Paulo state. 


\section{Introdução}

O setor sucroalcooleiro brasileiro tem uma longa trajetória histórica que se caracterizou, em alguns momentos, pela forte intervenção do Estado na produção e na comercialização e, em outros, pela desvinculação do governo de muitas atividades. Nos momentos de maior participação do Estado, os fornecedores de cana tinham garantida a sua participação na moagem das unidades processadoras. Após a desregulamentação do setor, essa garantia foi extinta, permanecendo sob decisão da usina a forma de abastecimento que deveria escolher.

No Brasil, no setor sucroalcooleiro, observam-se diferentes estruturas de governança no fornecimento de cana-de-açúcar para a usina, que variam desde a forma com menor nível de controle, o mercado spot, até a de maior nível de coordenação das atividades, a de integração vertical, aparecendo, entre ambos, uma variedade de mecanismos híbridos.

Além da diversidade de estruturas de governança entre as unidades produtoras, também há pluralidade nas transações, ou seja, uma mesma unidade produtora possui mais de uma estrutura de governança.

Este artigo tem como objetivo geral analisar os fatores que justificam a opção da usina por formas plurais ou por formas singulares de governança em um mesmo tipo de transação. Como objetivos específicos, têm-se: (a) caracterizar as diferentes estruturas de governança presentes na transação de cana-de-açúcar; (b) mostrar o nível de pluralidade que existe em cada usina pesquisada; e (c) analisar os fatores que influenciam na participação de cada estrutura de governança para a usina.

A justificativa para o desenvolvimento dessa pesquisa pauta-se no fato de que os estudos sobre as formas de governança e a pluralidade das mesas presentes em determinados elos da cadeia sucroalcooleira estão se desenvolvendo para vários setores. No Brasil, são poucas as aplicações sobre as formas plurais de governança, como será visto na revisão de literatura. No setor sucroalcooleiro ainda restam algumas lacunas, especialmente sobre a pluralidade nas transações no fornecimento de cana-de-açúcar.

Para o alcance dos objetivos deste artigo, foi realizada uma pesquisa de campo com a aplicação de entrevistas aos responsáveis pela decisão nas usinas sobre o abastecimento de matéria-prima para processamento. $\mathrm{O}$ conjunto de usinas analisadas (houve solicitação de sigilo quanto ao nome das usinas e à exata localização) totalizou um número de dez unidades processadoras de cana-de-açúcar na região oeste do Estado de São Paulo.

Este artigo está dividido em 4 partes, além da introdução e da conclusão. Na primeira, será apresentado um levantamento bibliográfico sobre formas plurais de governança. Em seguida, será apresentada a caracterização da pesquisa; na terceira parte serão analisadas as estruturas de governança presentes na transação de cana de açúcar; e, por fim, a pluralidade no abastecimento de cana.

\section{Formas Plurais de Governança e Aplicações}

Segundo Bradach e Eccles (1989), as formas plurais são consideradas como um arranjo no qual distintos mecanismos de controle organizacional são operados simultaneamente para a mesma função em uma mesma firma. Para Silva e Azevedo (2007, p. 149), "as denominações 'formas plurais' e 'mix contratual' são aqui preferidas para o melhor expressar a ideia de um portfólio de estruturas governadas pela firma". Perryman e Combs (2012) afirmam que as formas plurais existem quando gerentes usam dois proprietários para desempenhar uma atividade.

Algumas das contribuições sobre formas plurais podem ser sumarizadas na Tabela 1. 
Tabela 1

\section{Contribuições sobre Formas Plurais}

\begin{tabular}{|c|c|}
\hline Autor (ano) & Contribuições \\
\hline Botti, Briec e Cliquet (2007) & Formas plurais são mais comuns do que singulares. \\
\hline Silva e Azevedo (2007) & $\begin{array}{l}\text { Dividem os argumentos para a existência das formas plurais: transações } \\
\text { que se diferenciam em dos atributos; transações similares; transitoriedade } \\
\text { e estabilidade das formas plurais. Além disso, mostraram que as formas } \\
\text { organizacionais são mais diferenciadas do que mostra a literatura. }\end{array}$ \\
\hline Lafontaine e Shaw (2001) & Analisam os determinantes da proporção de lojas próprias e franqueadas. \\
\hline Bradach e Eccles (1989) & $\begin{array}{l}\text { Desenvolveram um corpo teórico focando em três mecanismos de } \\
\text { controle das transações: preço, autoridade e confiança. }\end{array}$ \\
\hline Zylbersztajn e Nogueira (2002) & $\begin{array}{l}\text { A coexistência de arranjos contratuais alternativos pode ser explicada } \\
\text { por: (1) dependência de rota; (2) diferentes ambientes institucionais; ( } 3 \text { ) } \\
\text { ajuste entre formas de governança atuais e futuras; e (4) competências } \\
\text { diferenciais. }\end{array}$ \\
\hline Pénard, Raynaud e Saussier (2003) & $\begin{array}{l}\text { As formas plurais têm sido estudadas como uma estratégia de equilíbrio e } \\
\text { um fenômeno estável por alguns autores. }\end{array}$ \\
\hline Botti et al. (2007) & Eficiência das formas plurais nas cadeias de hotéis. \\
\hline Perrigot, Cliquet e Piot-Lepetit (2009) & $\begin{array}{l}\text { As cadeias de hotéis que possuem a pluralidade organizacional tem } \\
\text { melhor desempenho quando mesclam eficiências técnicas e de escala. }\end{array}$ \\
\hline Dant, Perrigot e Cliquet (2008) & $\begin{array}{l}\text { Autores mostram que a proporção de companhias próprias é quase três } \\
\text { vezes maior na França e no Brasil quando comparadas aos EUA. }\end{array}$ \\
\hline Kranz e Lewin-Solomons (2008) & $\begin{array}{l}\text { Nas franquias americanas de fast food, o compromisso contratual para } \\
\text { padrões de comportamento mais uniforme é preferível se a fração de } \\
\text { lojas próprias é suficientemente elevada. }\end{array}$ \\
\hline Mello e Paulillo (2010) & $\begin{array}{l}\text { Na citricultura, a indústria é o canal de distribuição preferido do } \\
\text { citricultor, em especial com contratos que determinem garantias de venda } \\
\text { e recebimento. }\end{array}$ \\
\hline Perrigot e Herrbach (2012) & $\begin{array}{l}\text { Mostram as desvantagens das formas plurais em termos de cultura e coesão } \\
\text { da rede, custos e conflitos. }\end{array}$ \\
\hline
\end{tabular}

Os estudos sobre formas plurais concentraram-se, em sua maior parte, na análise das franquias e, segundo Zylbersztajn e Nogueira (2002), sobre a estabilidade dos múltiplos contratos simultâneos. Para Botti et al. (2007), as formas plurais tendem a ser mais populares quando comparadas aos sistemas formados puramente por franquias ou puramente por companhias próprias.

Silva e Azevedo (2007), na mesma linha de Botti et al. (2007), apontam que as organizações que se utilizam do franchising possuem um percentual de lojas próprias juntamente com as franqueadas - pluralidade nas formas organizacionais - mostrando que os atores não escolhem uma única estrutura de governança, mas um mix de formas contratuais para reger um conjunto de transações.

Silva e Azevedo (2007) organizaram os argumentos sobre formas plurais em três grupos. Em um primeiro grupo, o argumento é de que as formas organizacionais podem ser plurais se as transações forem diversas (grifo nosso), distinguindo-se em pelo menos um dos seus clássicos atributos: especificidade dos ativos, incerteza e frequência, e que essa heterogeneidade estaria associada à incapacidade dos agentes de escolherem a solução mais eficiente, compatíveis com o modelo de Williamson (1991). "As diversas relações entre franqueador e as lojas constituiriam transações distintas, com atributos distintos e, portanto, associadas a estruturas de governança distintas" (Silva \& Azevedo, 2007, p. 133). 
O segundo grupo sugere a escolha das diferentes estruturas de governança na condução das transações similares (grifo nosso) que compartilham dos mesmos atributos. Nesse grupo, admite-se que essas transações podem resultar em formas plurais, como apontaram no caso das franquias - lojas próprias convivendo com franqueadas. Dentro desse mesmo grupo, há duas vertentes que afirmam que formas plurais seriam transitórias e que prevaleceriam uma ou outra estrutura de governança (Zylbersztajn \& Nogueira, 2002).

Para Zylbersztajn e Nogueira (2002), a coexistência de arranjos contratuais alternativos é um enigma para a literatura que se baseia no alinhamento eficiente e pode ser explicada por: (a) dependência de rota; (b) diferentes ambientes institucionais; (c) uma situação de ajuste entre formas de governança atuais e futuras, movidas por modificações nas características das transações, configurando uma situação de desequilíbrio e (d) competências diferenciais, desenvolvidas a partir de rotinas específicas intransferíveis, o que gera barreiras para a adoção de um arranjo contratual novo e superior.

Zylbersztajn e Nogueira (2002) afirmam que a coexistência de arranjos diferentes pode estar relacionada ao ambiente institucional que pode, por exemplo, induzir a um determinado arranjo vertical de produção ou dificultar a implantação de um mesmo arranjo em regiões que não apresentem os mesmos incentivos institucionais.

Nesse mesmo grupo, há uma subdivisão sobre a proporção de lojas próprias e franqueadas. Para uns, o número de lojas próprias se reduziria com o tempo, dando lugar às franqueadas, e existiriam apenas como forma de sinalização de características relevantes aos franqueados (Gallini \& Lutz, 1992; Scott, 1995); a outra caminha no sentido inverso utilizando o argumento da propriedade e, assim, afirmam que as franquias seriam substituídas pelas unidades próprias com o passar do tempo (Dant, Paswan, \& Stanworth, 1996).

O terceiro grupo defende a hipótese da estabilidade do emprego de formas plurais ao longo do tempo, e a decisão sobre um percentual ótimo de unidades próprias e franqueadas pode ser interpretada como uma tentativa de prover maior controle e capacidade de barganha sobre seus franqueados, e assim diminuir a possiblidade de má utilização da marca. Entre esses autores, podem ser citados Lafontaine e Shaw (2001), Bradach e Eccles (1989) e Pénard et al. (2003).

Em relação às franquias, a pesquisa de Lafontaine e Shaw (2001) demonstrou que a proporção de companhias próprias dentro da rede tende a decrescer nos primeiros anos do negócio e se estabilizar. Essa estabilidade é interpretada como uma evidência de que as cadeias objetivam uma dada proporção de companhias próprias e franquias, o que é específico de cada setor.

Um dos determinantes da proporção de companhias próprias e franqueadas, sugerido por Lafontaine e Shaw (2001), é a experiência e o valor do royalty pago. Quanto à primeira, firmas que se mantiveram distantes da atividade do franchising por um longo tempo tendem a exibir uma fração maior de companhias próprias. Quanto ao royalty pago, quanto maiores forem os pagamentos, maiores serão os incentivos para o franqueador controlar suas unidades e preservar o capital da marca.

Na mesma linha dos autores que afirmam que as formas plurais são estáveis ao longo do tempo, estão Bradach e Eccles (1989), que desenvolveram um corpo teórico que focou nos três mecanismos de controle que consideram governar as transações entre os atores: preço, autoridade e confiança, contrariando as contribuições tradicionais que visam a mercados e a hierarquias como mecanismos de controle mutuamente exclusivos, assim como Eccles e White (1988). Para Bradach e Eccles (1989), preço, autoridade e confiança são independentes e podem ser combinados em uma variedade de formas.

Para tratar sobre preço e autoridade, Bradach e Eccles (1989) dividem a análise em duas partes. Primeiro tratam sobre as variáveis, considerando a firma e depois os mercados. Em nenhum outro lugar o mix de preços e autoridade é tão visível quanto na firma multidivisional. Para eles, a firma moderna é reconhecida por introduzir características de mercados dentro de hierarquias. 
Ver as transações como sendo governadas pelo mecanismo de preços ou autoridade ofusca as formas multifacetadas que os executivos usam para mesclar esses mecanismos de controle para gerenciar suas operações. Bradach e Eccles (1989) afirmam que forças similares também são encontradas nos mercados.

Quanto à confiança, Bradach e Eccles (1989) afirmam que é um tipo de expectativa que ameniza o medo de que um parceiro envolvido na troca aja com oportunismo. Gonçalves (2008) desenvolveu pesquisa sobre o tema confiança na vitivinicultura gaúcha, e apresentou uma estrutura teórica sobre o assunto a partir de vários autores. Essa estrutura foi organizada de acordo com os componentes e determinantes da confiança, os tipos de confiança e a relação entre confiança e as dimensões da análise da ECT.

A crítica de Bradach e Eccles (1989) ao corpo teórico tradicional da Nova Economia Institucional é a de que mercados e hierarquias têm sido vistos como mecanismos alternativos de se alocar recursos. Uma das contribuições seminais a respeito desse assunto é a de Coase (1937), desenvolvida posteriormente por Williamson $(1975,1985)$, para o qual as formas de governança são determinadas para contornar o problema da racionalidade limitada dos agentes e inibir o comportamento oportunista. Assim, Williamson $(1971,1985)$ procurava argumentar que os arranjos organizacionais eram uma resposta às considerações sobre eficiência.

Bradach e Eccles (1989) discordam da concepção de que as três formas de governança são mutuamente exclusivas. Para eles, os três mecanismos estudados, preço, autoridade e confiança, são conceitos úteis que reconhecem serem independentes e podem ser combinados uns com os outros em uma variedade de formas.

As transações são enraizadas em um contexto de outras transações, assim como em um contexto social, focando especialmente as formas plurais - um arranjo em que mecanismos de controle distintos são operados simultaneamente para a mesma função em uma mesma firma.

O objeto de pesquisa de Bradach e Eccles (1989) foi a indústria automotiva. Nessa, a hipótese lançada foi a de que a experiência em produzir uma parte tem dois efeitos que empurram as decisões de comprar ou produzir em direções opostas. Primeiro, a experiência do comprador pode resultar em uma vantagem de custo de produção para o comprador sobre o fornecedor. Segundo, compradores com uma história de produzir um componente têm melhor informação sobre o processo de produção, e os fornecedores são menos capazes de se envolver em uma barganha oportunista.

Ainda na pesquisa de Bradach e Eccles (1989), observa-se que, quando uma companhia produz, assim como compra, ou seja, mantém a pluralidade nas suas transações, ela não apenas possui informação que pode ser utilizada para gerenciar o subcontratado, mas as ideias e as inovações do subcontratado podem ser trazidas para dentro dos negócios da companhia. Tais arranjos desempenham um papel destacável no balanceamento das economias de escala na cadeia de valor e reduzem a vulnerabilidade da companhia no caso de greves e escassez; também é reconhecido que tais formas abrem um novo corredor de informação sobre as atividades dos competidores.

A aposta em formas únicas de governança apresenta obviamente dificuldades. Bradach e Eccles (1989) colocam que o contrato é problemático sem uma experiência interna e as dificuldades associadas com a hierarquia são amplamente reconhecidas. $\mathrm{O}$ recurso para essas dificuldades pode ser o uso simultâneo de dois mecanismos, criando em essência a competição entre eles.

A franquia é um exemplo de forma plural e, para Silva e Azevedo (2007), o maior objeto dos estudos sobre esses arranjos organizacionais. Quase todos os sistemas de franquias são compostos por unidades próprias e franqueadas. As unidades próprias são gerenciadas em uma estrutura hierárquica que fornece para a companhia o lucro total, mas fica sujeita ao comportamento dos gerentes, sendo necessário monitorá-los, ao contrário das franquias, nas quais os administradores recebem parte dos lucros e tem esse incentivo para não agir de forma oportunista. A escolha entre eles é função de circunstâncias - quem vem com a ideia de um novo local, de quem tem dinheiro, se gerentes 
qualificados estão disponíveis, e assim por diante. De qualquer forma, observa-se que os gerentes seniors reconhecem o controle indireto permitido pelas formas plurais (Bradach \& Eccles, 1989).

As formas plurais, segundo Pénard et al. (2003), têm sido estudadas como uma estratégia de equilíbrio e um fenômeno estável, ao contrário do que afirmam alguns autores, para os quais, inclusive uma grande parte a literatura, as formas plurais são um fenômeno transitório.

Entre os argumentos a favor da estabilidade das formas plurais citados por Bradach (1997), há ênfase naqueles sobre as complementaridades entre arranjos contratuais para manter a qualidade e a homogeneidade da concepção dos negócios entre as unidades, enquanto promove inovação. LewinSolomons (1999) afirmam que a existência dessas formas advém do artifício usado pelo franqueador para dar aos seus franqueados incentivos para inovar. Em unidades homogêneas, como as franquias, a estabilidade das formas plurais é uma forma de induzir esforços para o desenvolvimento da marca (Bai $\&$ Tao, 2000).

É relevante considerar que, em todos esses argumentos, as formas plurais aparecem como uma solução eficiente em abrandar os riscos contratuais ligados com assimetria informacional, compromissos imperfeitos e contratos incompletos, sugerindo que a cadeia com uma proporção estável de companhias próprias poderia ser mais eficiente no longo prazo do que em situações em que há os extremos - todas as unidades franqueadas ou todas próprias.

Cliquet e Croizean (2002), em estudo realizado sobre o varejo de cosméticos, observaram que as formas plurais parecem ser atrativas nesse segmento, porém, as decisões sobre qual a proporção de lojas franqueadas ou próprias dependem da posição do operador dentro do ciclo de vida da cadeia em relação à cobertura espacial, ou seja, o serviço não é suficientemente rentável para os maiores varejistas, pois o custo por metro quadrado é muito elevado. O problema para operadores da cadeia recai na sua capacidade de combinar o número e a qualidade de companhias próprias para manter a cadeia, e o conceito de controle, sem causar transtornos para as franqueadas, além de recrutar franqueados que não conduzirão a maiores reestruturações nas localizações estratégicas.

Botti et al. (2007) demonstraram que nas cadeias de hotéis da França, as redes que possuíam formas plurais eram em média mais eficientes do que as que optavam por formas singulares totalmente franqueadas ou companhias próprias.

Ainda nas cadeias de hotéis francesas, Perrigot et al. (2009) complementam Botti et al. (2007), mostrando que as que possuem a pluralidade organizacional tem melhor desempenho quando mesclam eficiências técnicas e de escala. Elas constituem cadeias com as melhores práticas dentro da população em investigação com relação à escala de suas atividades. Essa diferença em termos de eficiência, segundo os autores, pode ser explicada pelo que de que os franqueadores com unidades próprias usam essas unidades como laboratórios para testar inovações, para controlar a difusão, a extensão e a evolução da marca. Ao mesmo tempo, os franqueadores se beneficiam das críticas externas e feedbacks advindos de seus franqueados com maior dinamismo e responsividade, elementos decorrentes de franqueados executarem seu próprio negócio.

Silva e Azevedo (2007) analisaram a existência de formas plurais no sistema de franquias de alimentos, comparando Brasil e França, e observaram que as formas organizacionais encontradas no franchising são mais diferenciadas do que mostra a literatura. Além da hierarquia, foram observadas três opções de contratos de franquia, diferindo-se quanto à exigência de capital, aos incentivos e à divisão de riscos. Observaram também que, o ambiente institucional é uma das principais variáveis explicativas que diferencia as formas encontradas no Brasil e na França. No Brasil, as redes não exploram por completo as possibilidades dos contratos como as observadas na França em função do sistema legal e as incertezas relacionadas às decisões judiciais.

Dant et al. (2008) realizaram uma pesquisa exploratória sobre pluralidade nas franquias, considerando as variáveis operacionalização e proporção de unidades próprias e franqueadas entre três países com diferenças culturais significativas: EUA, Brasil e França. Os resultados encontrados mostram que a proporção de companhias próprias é quase três vezes maior na França e no Brasil 
quando comparadas aos EUA. Os autores também mostram que, na amostra americana, três em cada oito indicadores demonstravam a ocorrência de formas plurais e, na amostra brasileira, dois indicadores influenciaram o fenômeno das formas plurais; já a amostra francesa não foi estatisticamente significante.

Kranz e Lewin-Solomons (2008) analisaram as cadeias de franquias americanas de fast food e constataram que um forte compromisso contratual para padrões de comportamento mais uniforme é preferível se a fração de lojas próprias é suficientemente elevada. Isso foi concluído a partir da obtenção de uma correlação positiva significativa entre a fração de companhias próprias e a ocorrência do referido compromisso.

Mello e Paulillo (2010) analisaram a pluralidade na cadeia citrícola paulista e observaram que a indústria é o canal de distribuição preferido do citricultor, em especial com contratos que determinem garantias de venda e recebimento. Outra opção, não tão frequente, é o mercado spot, que oferece:

os preços maiores, o recebimento à vista, a cobertura das despesas de colheita e transporte pelo comprador, a possibilidade de vender as frutas temporãs e as variedades não desejadas para o processamento e a redução de riscos associados à possível incompletude dos contratos realizados com a indústria (Mello \& Paulillo, 2010, p. 160).

Apesar dessa preferência pela indústria, de acordo com os autores, a escolha da forma de abastecimento na indústria ocorre pelo tamanho do citricultor, preferindo os citricultores maiores e o que necessitar para completar o abastecimento vem de produtores menores; distanciamento do produtor até a indústria, pois essa é uma transação com elevada especificidade locacional. Em função desses fatores, o citricultor obriga-se a buscar outros canais de distribuição, o que resulta na pluralidade nas transações. Nesse caso, os autores afirmam que há necessidades específicas por parte dos compradores que geram restrições e podem explicar a multiplicidade de canais de distribuição da laranja.

No segmento de outlets, Perrigot e Herrbach (2012), ao contrário dos autores anteriores, procuraram mostrar as desvantagens das formas plurais em termos de cultura e coesão da rede, custos e conflitos. Os conflitos nas governanças plurais surgem quando os franqueadores e franqueados estão localizados em áreas muito próximas, promovendo uma situação de extrema concorrência entre os dois. Para a manutenção dos benefícios dessa forma organizacional, é necessário que se reforce a cultura da rede e que se minimizem conflitos internos, além de manter franqueadores e franqueados na mesma direção, ou seja, mantendo a coesão.

\section{Caracterização da Pesquisa}

Quanto ao objetivo, esta pesquisa é de caráter descritivo, pois busca apresentar as características do objeto estudado: um grupo de usinas de açúcar e álcool concorrentes entre si.

Para realizar a descrição desse grupo, foi utilizada a estratégia de abordagem do tipo levantamento, que se deu por meio de uma entrevista aberta, realizada individualmente com os responsáveis pela decisão de abastecimento de cana-de-açúcar na usina - gerentes agrícolas e supervisores de contratos e parcerias, somando ao todo oito entrevistados (sete em usinas e um em associação) - permitindo captar informações de ordem qualitativa. Em outros casos, foi necessário o contato com as associações de fornecedores de cana, pois algumas usinas do grupo não se disponibilizaram a conceder a entrevista.

Apesar de terem sido realizadas oito entrevistas, foi possível coletar informações sobre dez unidades produtoras de açúcar e álcool, pois em dois casos as usinas pertenciam a um grupo. Assim, em uma mesma entrevista os responsáveis pelas informações relataram o que ocorria em duas unidades diferentes. 
As entrevistas duraram aproximadamente uma hora, e nelas foram levantadas questões referentes às formas de abastecimento de cana nas usinas, detalhes pertinentes aos contratos (tempo de duração, obrigações das partes e outras cláusulas), histórico das estruturas de governança nas usinas, relacionamento com contratados, formas mais adequadas de abastecimento, entre outras variáveis pertinentes a esta pesquisa.

A região para análise neste estudo está localizada em uma área considerada por Manzatto, Assad, Bacca, Zaroni e Pereira (2009) como de alta e média aptidão para a cultura de cana-de-açúcar a região oeste do Estado de São Paulo - e pela Secretaria de Agricultura e Abastecimento e Secretaria do Meio Ambiente (n.d.) como adequada (com algumas restrições e limitações ambientais e sem limitações ambientais) para a instalação de usinas de açúcar e/ou álcool, o que vem aumentando a concorrência entre usinas pela disponibilidade de terras e fornecedores de cana-de-açúcar.

Devido à elevada aptidão agrícola dessas localidades, há intensa ou considerável expansão de produção de cana-de-açúcar e também da concorrência por fornecedores desse produto e/ou por terras.

A delimitação do número de usinas foi traçada a partir de uma entrevista com um primeiro grupo de usinas, que mostrou que há intensa concorrência entre as usinas na região Oeste, seja por fornecedores, seja por terras.

Observou-se nas entrevistas de campo uma média de $40 \mathrm{~km}$ de distância das usinas até os canaviais, o que irá depender do mercado. Esse raio de busca é válido para momentos em que o mercado encontra-se com relativa estabilidade entre oferta e procura. Esse raio foi escolhido pela especificidade locacional que possui a cana-de-açúcar. A mesma, por possuir baixo valor agregado da carga em relação ao frete, não pode ser transportada a longas distâncias. Portanto, até $40 \mathrm{~km}$ de distanciamento de cada usina, elas podem concorrer por terras e fornecedores.

A partir dessa delimitação, foi traçado um raio de até $80 \mathrm{~km}$ das duas unidades de produção: Usina A (unidade 1) e Usina A (unidade 2) (40 km de busca por fornecedores das unidades da Cana A somados a $40 \mathrm{~km}$ de raio de busca de outras usinas), como mostra a Figura 1. A partir desse raio, existem fornecedores de cana e terras que podem ser de interesse comum entre as usinas.

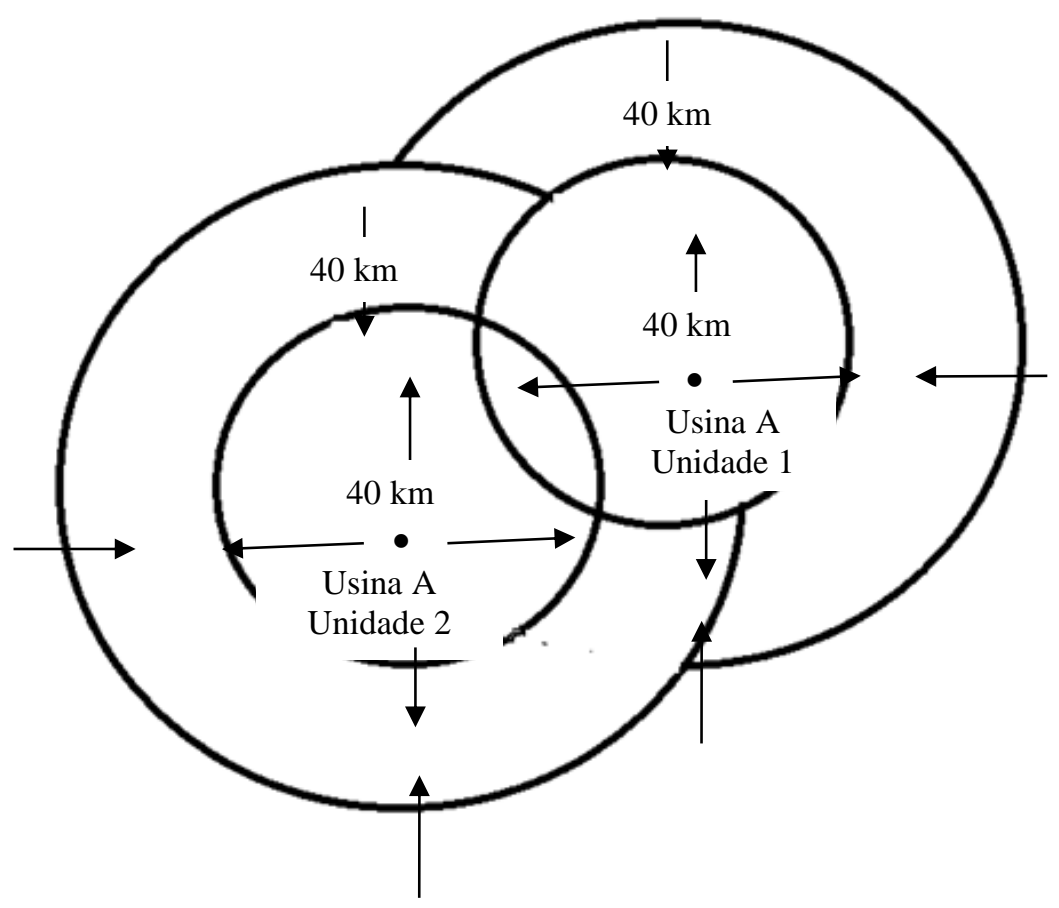

Figura 1. Delimitação da Área de Estudo. 
A partir deste recorte do mapa do Estado de São Paulo e do raio de busca por fornecedores e/ou terras, foram listadas as unidades com distanciamento de até $80 \mathrm{~km}$ das duas unidades da Usina A. Até esse distanciamento, havia 9 usinas concorrendo por fornecedores de cana e terras com a Usina A unidades 1 e 2 . Seus nomes, localidades exatas e capacidade serão omitidos por solicitação das usinas entrevistadas.

A essas usinas foi aplicado um roteiro de entrevista com questões abertas, com o intuito de identificar quais formas de abastecimento de matéria-prima a usina possui e quais as diferenças entre si. O roteiro de entrevista foi formulado a partir das variáveis apresentadas na revisão de literatura e de um levantamento sobre transações aplicadas ao setor (Amaral, 2009; Marques, 2009; Moraes, 2000, 2002; Neves \& Conejero, 2010; Ramos, 1999).

Amaral (2009) realizou pesquisa sobre as estruturas de governança adotadas por quatro grupos do setor sucroalcooleiro na região Centro-Sul. Nesta foi observada uma multiplicidade de arranjos no abastecimento de cana-de-açúcar, com maior participação de fornecedores externos e a possibilidade da especialização de cada um dos agentes sem sua atividade fim.

Marques (2009) apresentou características da produção industrial, em especial os custos relacionados à produção de açúcar e álcool pelas usinas. A partir desta, foi possível extrair informações sobre as peculiaridades de produção industrial e também agrícola, trabalhada com menor ênfase pelo autor, que podem afetar as escolha das transações, informações também trabalhadas por Moraes (2000, 2002).

Neves e Conejero (2010) apresentam estratégias competitivas e de crescimento utilizadas pelas usinas após a desregulamentação estatal do setor. Nesta obra, apresentam as diversas formas de abastecimento de cana-de-açúcar apresentadas na literatura, suas vantagens assim como desvantagens.

Já Ramos (1999) mostra as características do setor e sua evolução até a década final de regulamentação estatal do setor. Por esta obra, é possível obter informações sobre aspectos institucionais que podem interferir na escolha das estruturas de governança presentes no abastecimento.

As entrevistas foram realizadas entre os meses de dezembro/2011 e março/2012, período de entressafra, quando é possível encontrar os responsáveis pelas informações nas unidades de produção. Entre os meses de abril e novembro, período de safra, eles dedicam o tempo de trabalho à produção de campo.

\section{Estruturas de Governança Presentes nas Transações de Cana-de-açúcar}

As estruturas de governança observadas nas transações de cana-de-açúcar no Oeste Paulista variam desde a estrutura mais verticalizada - a integração vertical total (cana produzida em terras da própria usina) - até a de menor controle pelas usinas - o mercado spot (compra sem contrato ou compromisso). No intervalo dessas duas formas extremas, foram encontrados formatos com uma série de pequenas variações que foram agregados em três grandes conjuntos de estruturas de governança:

1. cana produzida em parceria: o proprietário cede a terra para a usina e recebe por ela uma parcela da cana que foi produzida. Nessa forma não há a incidência do IR sobre propriedade, reduzindo a carga tributária sobre a usina e também sobre o proprietário da terra;

2. cana proveniente de acionistas da usina (com ou sem contratos): pode haver ou não contrato e fornece certo grau de garantia para as usinas, já que é do interesse do acionista que a usina tenha elevado nível de lucratividade;

3. contratos com fornecedores que não possuem participação acionária na usina: a usina firma contrato de fornecimento com os fornecedores de cana-de-açúcar por prazo determinado. 
Nessas estruturas de governança intermediárias - ou híbridas - a forma de pagamento, as responsabilidades (preparo do solo, plantio, tratos culturais, corte, carregamento, transbordo e transporte), a disponibilidade de assistência técnica e a duração dos contratos são diferenciadas entre as usinas e também entre as transações em uma mesma usina, o que dá às transações uma variedade significativa, dificultando a organização de um número fixo de arranjos.

Quanto ao sistema de pagamentos, este pode ser diferenciado entre as usinas e para uma mesma usina. Nesta pesquisa, foram encontrados o sistema de pagamento de litros de álcool por tonelada de cana, Kg de ATR/tonelada (ATR fixo), ATR relativo, ATR apurado, Consecana e outras variações que incluem premiações pela qualidade da lavoura. Há usinas que optam por um determinado sistema, outras que possuem mais de um sistema e outras que fecham contratos flexíveis, nos quais o contratado escolhe qual parcela da produção deve receber sob qual forma de pagamento.

O tempo de duração dos contratos é atribuído de acordo com a idade do canavial. Quanto mais novo o canavial, maior é a duração do contrato. Há uma pequena variação entre as usinas na determinação desse ínterim: 1 (um para reforma) - 5-6 (cinco ou seis para colheita) anos. Essa variação irá depender da avaliação sobre as condições do canavial em produzir com uma qualidade aceitável para processamento e da disponibilidade para a realização da reforma.

As responsabilidades sobre preparo do solo, plantio, tratos culturais, corte, carregamento e transporte irão depender da tradição dos fornecedores, habilidades com a cultura e de sua capacidade financeira de arcar com o investimento necessário. Em casos de necessidade de mecanização das áreas, a usina é responsável por corte, carregamento, transbordo e transporte, pois o investimento nesses equipamentos é impeditivo para o fornecedor realizar essas atividades, porém quem arca com as despesas de transporte é o fornecedor. Essas despesas são descontadas no ato do pagamento pela cana recebida. Em outros casos, há formação de condomínios de fornecedores que constituem um agrupamento com uma estrutura administrativa própria com técnicos agrícolas e agrônomos que realizam o preparo do solo e orientam sobre tratos culturais. Também solicitam às usinas a recomendação varietal. Nessa forma de organização, a usina economiza em custos de orientação técnica. Em alguns casos, o condomínio possui o equipamento e o maquinário de CCT, o que reduz custos operacionais para a usina.

A Tabela 2 mostra a participação das estruturas de governança em cada uma das usinas pesquisadas. A primeira coluna refere-se às usinas, a segunda mostra qual a participação de cada uma delas no total moído pelo grupo, e as demais colunas apresentam a participação de cada estrutura de governança nas unidades de produção de açúcar e/ou álcool.

Tabela 2

Distribuição da Moagem e Participação das Estruturas de Governança

\begin{tabular}{|c|c|c|c|c|c|c|c|}
\hline \multirow[t]{2}{*}{$\begin{array}{l}\text { Grupo/ } \\
\text { Autônoma }\end{array}$} & \multirow[t]{2}{*}{ Usina } & \multirow{2}{*}{$\begin{array}{c}\text { Participação da } \\
\text { moagem no } \\
\text { grupo }(\%)\end{array}$} & \multicolumn{5}{|c|}{$\begin{array}{c}\text { Participação das estruturas de governança }{ }^{\mathrm{i}} \text { no } \\
\text { total de cana moída }\end{array}$} \\
\hline & & & $I V^{1}$ & $\mathbf{P A}^{2}$ & $A C^{3}$ & FC $^{4}$ & $\mathbf{M S}^{\mathrm{ii5}}$ \\
\hline Grupo 1 & A & $26,01 \%$ & $9 \%$ & $36 \%$ & $27 \%$ & $27 \%$ & - \\
\hline Autônoma & B & $7,51 \%$ & $3 \%$ & $41 \%$ & $32 \%$ & $24 \%$ & - \\
\hline Autônoma & $\mathrm{C}$ & $6,36 \%$ & $6 \%$ & $52 \%$ & $9 \%$ & $34 \%$ & - \\
\hline \multirow[t]{2}{*}{ Grupo 2} & D & $18,79 \%$ & $0 \%$ & $66 \%$ & $0 \%$ & $34 \%$ & - \\
\hline & E & $11,56 \%$ & $0 \%$ & $70 \%$ & $0 \%$ & $30 \%$ & - \\
\hline Autônoma & F & $8,09 \%$ & $0 \%$ & $0 \%$ & $0 \%$ & $100 \%$ & - \\
\hline Autônoma & G & $2,89 \%$ & $50 \%$ & $20 \%$ & $0 \%$ & $30 \%$ & - \\
\hline
\end{tabular}


Tabela 2 (continuação)

\begin{tabular}{|c|c|c|c|c|c|c|c|}
\hline \multirow[t]{2}{*}{$\begin{array}{l}\text { Grupo/ } \\
\text { Autônoma }\end{array}$} & \multirow[t]{2}{*}{ Usina } & \multirow{2}{*}{$\begin{array}{c}\text { Participação da } \\
\text { moagem no } \\
\text { grupo }(\%)\end{array}$} & \multicolumn{5}{|c|}{$\begin{array}{c}\text { Participação das estruturas de governança }{ }^{\mathrm{i}} \text { no } \\
\text { total de cana moída }\end{array}$} \\
\hline & & & IV $^{1}$ & $\mathbf{P A}^{2}$ & $\mathrm{AC}^{3}$ & $\mathrm{FC}^{4}$ & MSi5 \\
\hline Grupo 3 & $\mathrm{H}$ & $7,23 \%$ & $40 \%$ & $50 \%$ & $0 \%$ & $10 \%$ & - \\
\hline \multirow[t]{4}{*}{ Grupo 4} & I & $3,76 \%$ & $30 \%$ & $0 \%$ & $0 \%$ & $70 \%$ & - \\
\hline & $\mathrm{J}$ & $7,80 \%$ & $30 \%$ & $0 \%$ & $0 \%$ & $70 \%$ & - \\
\hline & Média & - & $16,8 \%$ & $33,5 \%$ & $6,8 \%$ & $42,9 \%$ & \\
\hline & Total & $100 \%$ & \multicolumn{3}{|c|}{$\sum \mathrm{IV} ; \mathrm{PA} ; \mathrm{AC}=\mathbf{5 7 , 1 \%}$} & \multicolumn{2}{|c|}{$\sum \mathrm{FC} ; \mathrm{MS}=\mathbf{4 2 , 9 \%}$} \\
\hline
\end{tabular}

Nota. Legenda: ${ }^{1} \mathrm{IV}$ : Integração vertical total; ${ }^{2} \mathrm{PA}$ : Parceria (quase integração); ${ }^{3} \mathrm{AC}$ : Cana de acionistas com ou sem contrato; ${ }^{4} \mathrm{FC}$ : Fornecedor contratado; ${ }^{5} \mathrm{MS}$ : Mercado spot.

${ }^{\mathrm{i}}$ Observando-se as variações quanto à duração dos contratos, responsabilidades e formas de pagamento. ${ }^{\mathrm{ii}} \mathrm{Em}$ alguns casos, os entrevistados não souberam afirmar qual o percentual de participação de cana spot no total de cana moída pela usina na última safra. Porém, em todos os casos, esse percentual foi considerado marginal ou irrisório.

- valores insignificantes.

O que se observa é que a soma das médias das formas mais verticalizadas - integração vertical, acionistas e parceria - e das de menor controle - fornecedores e fornecedor spot - são muito próximas, com a participação de fornecedores sendo preponderante entre as estruturas de governança. Apenas uma das usinas optou por singularidade no abastecimento de cana-de-açúcar - Usina $\mathrm{F}$-, o que se justificou pelas dificuldades financeiras pelas quais passou nos últimos anos e a obrigou a se desfazer das unidades próprias para sanar dívidas e cortar custos de produção.

\section{Pluralidade nas Transações de Cana-de-açúcar}

Bradach e Eccles (1989) afirmam que, quando se analisa a firma moderna, é possível observar um mix entre formas de governança, e que seria inadequado observar essas formas de governança como mutuamente excludentes. Nas transações de cana-de-açúcar nas usinas, esse mix é bastante evidente, diferenciando-se quanto à proporção de cada uma das estruturas de governança presentes, como mostrou a Tabela 2.

É possível afirmar que, além das variações entre as proporções de formas de governança entre setores como observado por Lafontaine e Shaw (2001), estas também se observam intrassetorialmente. No caso da existência de unidades próprias de produção - integração vertical - não há uma posição dominante quanto à quantidade de terras em propriedade das usinas. Um dos entrevistados lançou mão do conceito de custo de oportunidade para justificar a quantidade de cana proveniente de terras próprias, levando-se em consideração o quanto ganharia se o dinheiro investido em capital fixo estivesse aplicado em terras e o quanto teria que pagar em imposto de renda.

Em outro caso, o entrevistado afirmou que não há um cálculo exato sobre a proporção de cada uma das formas de governança. Porém, todos afirmaram que parte das terras em propriedade da usina é função de sua história, pois em todos os casos os fundadores tiveram que adquirir terras para iniciar a instalação das unidades. A proporção de terras próprias foi se alterando com a mudança de propriedade das usinas e da situação financeira de cada uma.

Também não há uma definição de qual a melhor estrutura de governança entre os entrevistados. Algumas - Usina B, C, G e H - citam que a melhor estrutura seria em forma de parcerias, pois fortalece a usina e diminui os riscos em relação ao abastecimento ao longo do ano, porém há sobrecarrega de atividades. Para eles, essa estratégia é ideal quando as condições financeiras da usina 
são boas. Outros - Usina A, D, E, F, I e J - citam que a melhor estratégia é a cana advinda de fornecedores contratados, pois torna a estrutura da usina mais enxuta e reduz custos de produção e administração de campo, porém a expõe muito à concorrência por fornecedores.

Lafontaine e Shaw (2001) constatam que, no caso das franquias, um dos determinantes da proporção de companhias próprias e franqueadas é a experiência e valor do royalty pago. Assim, quanto menor a experiência e/ou maior o valor do royalty pago pelas franqueadas, maior o interesse em manter uma quantidade menor de unidades próprias e vice-versa.

Quando se trata da transação de cana-de-açúcar, o valor pago nas parcerias é função da concorrência por terras e um dos determinantes na decisão sobre contratar parceiros ou fornecedores. Quanto à experiência, observou-se que, em unidades compradas por grupos não especializados na produção de açúcar e álcool - Usina D e E -, a preferência é por fornecedores.

As variáveis tratadas por Bradach e Eccles (1989) focam três mecanismos de controle no governo das transações entre os atores: preço, autoridade e confiança, sendo independentes e podendo ser combinados em uma variedade de formas.

Quanto à confiança, Bradach e Eccles (1989) afirmam que é um tipo de expectativa que alivia o medo de que um parceiro envolvido na troca aja de forma oportunista. Nas transações de cana-deaçúcar, o termo confiança foi mencionado com bastante frequência entre os entrevistados. Essa é mantida por meio de algumas ferramentas formais e informais. As formais se sustentam na condição financeira da usina, na disponibilidade de assistência técnica pela usina aos fornecedores e na realização de palestras e reuniões com os contratados. No caso das informais, foi mencionado que, depois da execução do contrato, ao contratado, seja parceiro ou fornecedor, não pode faltar atenção. As usinas, por meio de técnicos, agrônomos, supervisores de parcerias e gerentes, mantêm contato via telefonemas e visitas, o que é facilitado ou dificultado, dependendo do número de contratados.

A pluralidade nas transações, suas características e seus elementos para cada usina podem ser observados na Tabela 3.

Tabela 3

\section{Pluralidade nas Transações de Cana-de-açúcar}

\begin{tabular}{|c|c|c|c|c|c|c|c|c|c|c|}
\hline Pluralidade nas transações & $\mathbf{A}$ & B & $\mathbf{C}$ & D & $\mathbf{E}$ & $\mathbf{F}$ & G & $\mathbf{H}$ & $\mathbf{I}$ & $\mathbf{J}$ \\
\hline Presença de formas plurais & $\mathrm{x}$ & $\mathrm{x}$ & $\mathrm{X}$ & $\mathrm{x}$ & $\mathrm{x}$ & & $\mathrm{x}$ & $\mathrm{x}$ & $\mathrm{x}$ & $\mathrm{x}$ \\
\hline Redução da vulnerabilidade da usina & $\mathrm{x}$ & $\mathrm{x}$ & $\mathrm{x}$ & $\mathrm{x}$ & $\mathrm{x}$ & & $\mathrm{x}$ & $\mathrm{x}$ & $\mathrm{x}$ & $\mathrm{X}$ \\
\hline Abertura de canal de informações & $\mathrm{x}$ & $\mathrm{x}$ & $\mathrm{X}$ & $\mathrm{x}$ & $\mathrm{x}$ & $\mathrm{x}$ & $\mathrm{x}$ & & $\mathrm{x}$ & $\mathrm{x}$ \\
\hline Dependência de rota & $\mathrm{x}$ & $\mathrm{x}$ & $\mathrm{x}$ & $\mathrm{x}$ & $\mathrm{x}$ & & $\mathrm{x}$ & $\mathrm{x}$ & $\mathrm{x}$ & $\mathrm{x}$ \\
\hline Ambiente institucional & & $\mathrm{x}$ & & $\mathrm{x}$ & $\mathrm{x}$ & & & & & \\
\hline Ajuste entre formas de governança atuais e futuras & & $\mathrm{x}$ & & $\mathrm{x}$ & $\mathrm{x}$ & & & & & \\
\hline Pretensão de alterar a proporção das estruturas existentes. & & & & $\mathrm{x}$ & $\mathrm{x}$ & & $\mathrm{x}$ & & & \\
\hline $\begin{array}{l}\text { Pretensão de reduzir a participação ou extinguir algum } \\
\text { tipo de estrutura de governança. }\end{array}$ & & & & $\mathrm{x}$ & $\mathrm{x}$ & & $\mathrm{x}$ & & & \\
\hline
\end{tabular}

A não observância da mútua exclusividade entre as formas de governança, citada por Bradach e Eccles (1989), nas transações entre fornecedores/parceiros e usina, foi evidente na pesquisa. Apenas a Usina $\mathrm{F}$ apresentou uma estrutura de governança exclusiva - fornecedores contratados - o que se deveu como já mencionado anteriormente à sua situação financeira. As demais usinas apresentam um mix de estruturas de governança, com proporções diferentes de cada uma das formas entre elas. 
Os autores também afirmam que, se uma companhia produz e compra, é dada a ela a possibilidade de possuir informações que podem ser utilizadas para gerenciar o contratado, balancear as economias de escala, reduzir a vulnerabilidade da companhia no caso de greves e escassez, além de abrirem canal de informação sobre as atividades dos competidores.

Dessas possibilidades a que mais se destacou foi a redução da vulnerabilidade da usina em relação aos fornecedores, dado que existe a possibilidade de migrarem para outras usinas com o fim do contrato. A usina minimiza esse risco fechando contratos no prazo mais longo possível para evitar o desabastecimento e mantendo unidades próprias de produção.

A abertura como canal de informação também foi observada, pois muitas das informações obtidas de uma determinada usina complementaram as informações obtidas em outra. Houve inclusive relatos dos entrevistados sobre o que as usinas concorrentes praticavam.

Zylbersztajn e Nogueira (2002) apontam três razões para a coexistência de arranjos contratuais alternativos. A dependência de rota foi observada na maioria das usinas, pois o fato de, no ato de sua instalação, terem comprado terras, fez com que, ao longo dos anos, dependesse da cana proveniente dessas unidades.

A diferença nos ambientes institucionais também mostra como algumas usinas, normalmente as que pertencem a grupos e estão localizadas em regiões diferentes umas das outras, operem com formatação diferenciada de contratos. $\mathrm{O}$ ambiente institucional na região em que está instalada a Usina E não permite que ela possua a mesma forma de pagamento que a outra subsidiária do grupo - Usina D.

Observou-se também que a cultura de pagamento pela tonelada da cana-de-açúcar dificulta a implementação total do sistema Consecana pelas usinas. Em alguns casos, ele é usado, porém se faz presente com outras formas alternativas de pagamento.

Quanto à situação de ajuste entre formas de governança atuais e futuras, algumas usinas que iniciaram o processo de venda de açúcar em mercados futuros e/ou fecharam grandes contratos de comercialização precisaram optar pela compra de cana no mercado spot, pois a obrigação de cumprir o contrato fez com que as usinas tivessem que buscar cana-de-açúcar em distâncias maiores e/ou de fornecedores sem contrato - Usinas B, D, E, I e J.

Nas usinas, foi observado que não se pretende eliminar algum tipo de estrutura de governança, confirmando a não transitoriedade da pluralidade. O que se observou é que talvez pretendam mudar um pouco a proporção da participação de cada uma delas, o que dependerá da política dos gestores.

\section{Discussão dos Resultados}

A revisão de literatura mostrou que as formas plurais são encontradas em várias segmentações da atividade econômica, não sendo possível afirmar que exista uma ou outra forma predominante de estrutura de governança em cada um desses, assim como nesta pesquisa.

As entrevistas realizadas no período mencionado na metodologia permitiram identificar as diferentes formas de abastecimento, suas características, vantagens e desvantagens presentes em cada uma das estruturas de governança para o grupo estudado. A extensão desses estudos poderia identificar outras formas de abastecimento além das citadas na Tabela 2, pois o número de usinas pesquisadas é relativamente pequeno em relação ao total de usinas no Brasil - aproximadamente 400 em todo o território (Ministério da Agricultura, Pecuária e Abastecimento [MAPA], 2013).

Esta pesquisa pautou-se em um grupo relativamente pequeno de usinas, não sendo possível tirar conclusões para o setor como um todo, pois, como mencionado, as usinas no Brasil são numerosas e 
estão distribuídas em localidades com níveis diferentes de concorrência por terras e matéria-prima, e também em diferentes ambientes institucionais. Essas diferenças podem levar a diversas conclusões sobre qual a melhor estrutura para coordenar o negócio da cana-de-açúcar e se há necessidade de balanceá-las.

$\mathrm{Na}$ localidade onde foi realizado este estudo, foi possível observar que as formas plurais existem, pois há necessidade de balancear os riscos e as desvantagens das formas únicas de governança. A manutenção da integração vertical total, apesar do nível mais elevado de segurança que promove, gera custos fiscais relacionados à manutenção de patrimônio pelas usinas.

Os contratos de parceria levam a usina a ter controle total sobre o resultado, pois permitem a ela o planejamento de longo prazo com controle da qualidade da cana-de-açúcar produzida, porém exige que ela possua pessoal qualificado para tal e arque com os custos e riscos da produção.

Já o fornecedor contratado reduz a participação da usina no campo, permitindo-lhe focar na produção industrial, porém a qualidade da matéria-prima, que é essencial para a usina obter eficiência industrial técnica e econômica, fica dependente da tradição do mesmo em produzi-la e do seu comprometimento com a manutenção do canavial.

A manutenção de estruturas de governança combinadas reduz a vulnerabilidade das usinas para cada uma das variáveis citadas anteriormente. Além disso, abre um canal de informação entre os que operam diretamente no campo e aqueles que possuem experiência industrial, o que é relevante para grupos econômicos que estão comprando usinas no Brasil, mas não necessariamente são especializados na produção de cana.

\section{Conclusões}

A pluralidade é um fenômeno presente nas transações em vários setores econômicos, conforme mencionado na revisão de literatura. Nesta pesquisa, observou-se que há pluralidade nos diferentes níveis de análise: transações com características diferentes, similares e para uma mesma transação. Além disso, observou-se que seu nível se mostrou diferenciado entre as unidades estudadas. Há unidades que possuem todas as formas de abastecimento listadas anteriormente, outras que possuem algumas das formas e outras que optam pela singularidade.

As opções pelas formas plurais normalmente estão relacionadas à elevada imobilização de capital fixo quando se mantêm formas totalmente verticalizadas e, no extremo, ao nível de exposição que promovem as formas com menor controle, como é o caso dos fornecedores contratados e spot.

As formas singulares, observadas em apenas uma das unidades pesquisadas que optou pela manutenção apenas de fornecedores contratados, existem, neste caso, pela condição financeira da usina, pois a manutenção de unidades próprias ou em parceria elevaria os custos de produção e administrativos, o que não seria viável, dada a situação delicada pela qual passa.

As estruturas de governança presentes mostram uma variedade entre integração vertical e mercado spot. Essa variedade é verificada nos detalhes dos contratos entre usinas e parceiros, e usinas e fornecedores contratados. Os arranjos entre os agentes envolvidos na transação se diferenciam pela duração dos contratos, pelas atribuições estabelecidas a cada parte e pelo sistema de remuneração.

As estruturas mais presentes na opção das usinas no abastecimento são as parcerias e os fornecedores contratados, pois geram menor imobilização de capital e segurança de abastecimento de cana no longo prazo, facilitando o planejamento das usinas. As estruturas extremas - integração vertical e mercado spot - são menos presentes. A integração vertical gera elevados custos de imobilização de capital, além de não estar facilmente disponível para as usinas a aquisição de terras na região estudada por dois fatores: o preço das terras e a ocupação por pastagens. Já o mercado spot, com presença marginal em 
relação às demais estruturas, é caracterizado por um nível demasiado de baixo controle, o que dificulta o planejamento de longo prazo da usina.

Os arranjos de abastecimento mostraram algum grau de competição. Há relatos de que fornecedores contratados estão transferindo suas unidades para a condição de parcerias. Isso ocorre em casos nos quais os fornecedores estão descapitalizados para a reforma de canaviais ou a família envelheceu para continuar administrando a produção de cana. Também há casos de fornecedores parceiros que estão mudando para a condição de parcerias, pois ambicionam ganhar por produtividade, o que não é possível na situação de parceira. Sob decisão da usina, a instabilidade a competição dos arranjos se mostrou maior, pois algumas desejam aumentar a participação de uma estrutura de governança em detrimento da outra.

Além disso, observou-se uma relativa estabilidade em cada arranjo, ou seja, sem significativas alterações na renegociação contratual. Ainda seria interessante verificar qual o nível de competição entre os arranjos realizando uma análise com foco nos fornecedores e parceiros naquela região.

Este artigo objetivou explorar as decisões sobre produzir ou não nas empresas para além da microeconomia tradicional, que aponta que esta decisão é uma função dos custos de produção, e da Economia dos Custos de Transação, que analisa uma transação individualmente, não abarcando o conjunto delas, que leva a um mesmo resultado. Nesse sentido, o trabalho buscou contribuir para o entendimento das decisões tomadas pelas empresas contemporâneas dentro do segmento do agronegócio e sob o foco da gestão da transação e não apenas da produção. Neste caso, o trabalho descobriu a presença de formas plurais de coordenação das negociações, o que representa uma vantagem para as empresas de processamento sucroalcooleiro que foram estudadas.

A pesquisa teve caráter fundamentalmente qualitativo, portanto, não permitindo inferências ou outras análises estatísticas aprofundadas. A falta desse tipo de análise não permitiu aos autores realizar estudos matematicamente embasados sobre as eficiências das formas de abastecimento.

Esta pesquisa foi realizada em uma área de intensa concorrência por cana-de-açúcar e de terras para produção da matéria-prima sucroalcooleira. Recomenda-se que este estudo seja estendido para áreas não tradicionais de produção de cana-de-açúcar, nas quais ocorre expansão canavieira ou mesmo com ambientes institucionais diferentes da região centro-sul do Brasil. Assim, seria possível verificar as semelhanças e as diferenças das tomadas de decisões das empresas de processamento sucroalcooleito sob ambientes institucionais e concorrenciais diferentes.

\section{Referências}

Amaral, R. O. (2009). Análise da transação de suprimento de cana-de-açúcar e os relacionamentos interorganizacionais (Dissertação de mestrado). Universidade de São Paulo, Ribeirão Preto, SP, Brasil.

Bai, C.-E, \& Tao, Z. (2000). Contract mixing in franchising as a mechanism for public-good provision. Journal of Economics and Management Strategy, 9(1), 85-113. doi: 10.1111/j.14309134.2000.00085.x

Botti, L., Briec, W., \& Cliquet, G. (2009). Plural forms versus franchise and company-owned systems: A DEA approach of hotel chain performance. The International Journal of Management Science - Omega, 37(3), 566-578. doi: 10.1016/j.omega.2007.12.002

Bradach, J. L. (1997). Using the plural form in the management of retail chains. Administrative Science Quarterly, 42(2), 276-303. 
Bradach, J. L., \& Eccles, R. G. (1989). Price, authority, and trust: from ideal types to plural forms. Annual Review of Sociology, 15(1), 97-118. doi: 10.1146/annurev.soc.15.1.97

Cliquet, G., \& Croizean, J.-P. (2002). Towards plural forms, franchising/company-owned systems, in the French cosmetics retail industry. International Journal of Retail \& Distribution Management, 30(5), 238-250. doi: 10.1108/09590550210426408.

Coase, R. H. (1937). The nature of the firm. Economica, New Series, 4(16), 386-405. doi: $10.1111 / \mathrm{j} .1468-0335.1937 . t b 00002 . x$

Dant, R. P., Paswan, A. K., \& Stanworth, J. (1996). Ownership redirection trends in franchising: a cross-sectoral investigation. International Journal of Entrepreneurial Behavior and Research, 2(3), 48-67. doi: 10.1108/13552559610153252

Dant, R. P., Perrigot, R., \& Cliquet, G. (2008). A cross-cultural comparison of the plural forms in franchise networks: United States, France, and Brazil. Journal of Small Business Management, $46(2), 286-311$.

Eccles, R. G., \& White, H. C. (1988). Price and authority in inter-profit center transactions. American Journal of Sociology, 94(Supl.), S17-S51.

Gallini, N. T., \& Lutz, N. A. (1992). Dual distribution and royalty fees in franchising. Journal of Law, Economics, \& Organization, 8(3), 471-501.

Gonçalves, W. M. (2008). Confiança, ECT e formas organizacionais: um framework aplicado na vitivinicultura da serra gaúcha e do vale do São Francisco (Tese de doutorado). Universidade Federal do Rio Grande do Sul, Porto Alegre, RS, Brasil.

Kranz, S., \& Lewin-Solomons, S. B. (2008). Decision structures in franchise systems of the plural form [Discussion Paper]. Bonn Econ Discussion Papers, University of Bonn, Germany.

Lafontaine, F., \& Shaw, K. L. (2001). Targeting managerial control: evidence from franchising [Working Paper $\mathrm{n}^{\circ}$ 8416]. National Bureau of Economic Research, Cambridge, MA. Recuperado de http://www.nber.org/papers/w8416.pdf?new_window=1

Lewin-Solomons, S. B. (1999). Innovation and authority in franchise systems: an empirical exploration of the plural form [Working Paper $\mathrm{n}^{\circ}$ 0015]. Cambridge Working Papers in Economics, Cambridge, United Kingdom. Recuperado de http://www.econ.cam.ac.uk/research/repec/cam/pdf/wp0015.pdf

Manzatto, C. V., Assad, E. D., Bacca, J. F. M., Zaroni, M. J., \& Pereira, S. E. M. (2009). Zoneamento agroecológico da cana-de-açúcar. Rio de Janeiro: Embrapa Solos.

Marques, P. V. (Coord.). (2009). Custo de produção agrícola e industrial de açúcar e álcool no Brasil na safra 2007/2008 (Relatório). Piracicaba: Universidade de São Paulo, Escola Superior de Agricultura "Luiz de Queiroz", Programa de Educação Continuada em Economia e Gestão de Empresas/Departamento de Economia, Administração e Sociologia.

Mello, F. O. T., \& Paulillo, L. F. O. (2010). Formas plurais de governança no sistema agroindustrial citrícola paulista. Revista de Economia e Sociologia Rural, 48(1), 135-159. doi: 10.1590/S010320032010000100007

Ministério da Agricultura, Pecuária e Abastecimento. (2013). Relação das unidades produtoras cadastradas no departamento de cana-de-açúcar e agroenergia. Recuperado de http://www.agricultura.gov.br/arq_editor/file/Desenvolvimento_Sustentavel/Agroenergia/Orient acoes_Tecnicas/Usinas\%20e\%20Destilarias\%20Cadastradas/DADOS_PRODUTORES_15_02_ 2013.pdf 
Moraes, M. A. F. D. de (2000). A desregulamentação do setor sucroalcooleiro do Brasil. Americana: Caminho Editorial.

Moraes, M. A. F. D. de (2002). Desregulamentação da agroindústria canavieira: novas formas de atuação do Estado e desafios do setor privado. In M. A. F. D. Moraes \& P. F. A. Shikida (Orgs.), Agroindústria canavieira no Brasil: evolução, desenvolvimentos e desafios (Cap. 1, pp. 21-42). São Paulo: Editora Atlas.

Neves, M. F., \& Conejero, M. A. (2010). Estratégias para a cana no Brasil. Um negócio de classe mundial. São Paulo: Atlas.

Pénard, T., Raynaud, E., \& Saussier, S. (2003). Dual distribution and royalty rates in franchised chains: an empirical analysis using French data. Journal of Marketing Channels, 10(3), 5-31. doi: 10.1300/J049v10n03_01

Perrigot, R., Cliquet, G., \& Piot-Lepetit, I. (2009). Plural form chain and efficiency: insights form the french hotel chains and the DEA methodology. European Management Journal, 27(4), 268-280. doi: 10.1016/j.emj.2008.11.001

Perrigot, R., \& Herrbach, O. (2012). The plural form from the inside: a study of franchisee perception of company-owned outlets within their network. International Journal of Retail \& Distribution Management, 40(7), 544-563. doi: 10.1108/09590551211239855

Perryman, A. A., \& Combs, J. G. (2012). Who should own it? An agency-based explanation for multioutlet ownership and co-location in plural forms franchising. Strategic Management Journal, 33(4), 368-386. doi: 10.1002/smj.1947

Ramos, P. (1999). Agroindústria canavieira e propriedade fundiária no Brasil. São Paulo: Hucitec.

Scott, F. A., Jr. (1995). Franchising vs. company ownership as a decision variable of the firm. Review of Industrial Organization, 10(1), 69-81. doi: 10.1007/BF01024260

Secretaria de Agricultura e Abastecimento e Secretaria do Meio Ambiente. (n.d.). Zoneamento agroambiental para o setor sucroalcooleiro. São Paulo: Autor. Recuperado de http://www.ciiagro.sp.gov.br/Zoneamento_Agroambiental/index.htm

Silva, V. L. S., \& Azevedo, P. F. de (2007). Formas plurais no franchising de alimentos: evidências de estudos de caso na França e no Brasil (1 ${ }^{\text {a }}$ Edição Especial). Revista de Administração Contemporânea, 11, 129-152. doi: 10.1590/S1415-65552007000500007

Williamson, O. E. (1971). The vertical integration of production: market failure considerations. The American Economic Review, 61(2), 112-123. doi: 10.2307/1816983

Williamson, O. E. (1975). Markets and hierarchies: analysis and anti-trust implications. New York: Free Press.

Williamson, O. E. (1985). The economic institutions of capitalism: firms, markets, relational contracts. New York: Free Press.

Williamson, O. E. (1991) Comparative economic organization: the analysis of discrete structural alternatives. Administrative Science Quarterly, 36(2), 269-296. doi: 10.2307/2393356

Zylbersztajn, D., \& Nogueira, A. C. L. (2002). Estabilidade e difusão de arranjos verticais de produção: uma contribuição teórica. Economia e Sociedade, 11(2), 329-346. 